LA-5920-MS

Informal Report

\section{Cooling Tower Modification for Intermittent Operation}

by

William S. Midkiff

UC-38

Reporting Date: March 1975

Issued: April 1975 
In the interest of prompt distribution, this report was not edited by the Technical Information staff.

Printed in the United States of America. Available from National Technical Information Service

U S Department of Commerce

5285 Port Royal Hoad

Sprnogield, VA 22151

Price: Printed Copy $\$ 400$ Microliche $\$ 2.25$

This report was prepured an an acrount of work pponeored

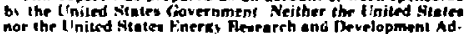

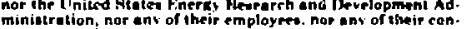

tractors. subrontractorn, or their emplayees. metee any

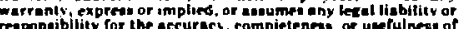

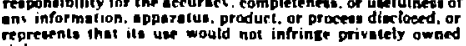

represents
rixhts. 


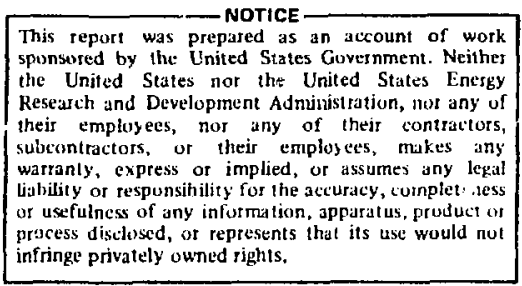

COOLING TOWER MODIFICATION FOR

JNTERMJTTENT OPERATION

by

William S. Midkiff

ABSTRACT

One of the cooling towers at LOS Alamos Scientific Laboratory is being operated intermittently. The cooling tower has been modified to restrict air flow and to keep the tower from drying out. The modifications are ralatively inexpensive, simple to operate, and have proved effective.

\section{INTRODUCTION}

A redwood cooling tower manufactured in 1957 (Fig. 1) has been used continuously for cooling one of the nuclear reactors at Los Alamos Scientific Laboratory (LASL). Recent limited usage of the reactor has resulter in intermittent use of the cooling tower. Operators of the reactor and cooling tower have been faced with preventing deterioration and freezing of the cooling tower.

The nuclear reactor at Omega site is the only operating reactor left at LASL. Presently, operation of the 8-MW reactor is limited to regular 8-hour work days. The operators would like to maintain the cooling water temperature in the reactor at its optimum operating temperature of $40 \mathrm{C}$, because temperature chances cause expansion and contraction of the reactor cooling chamber with resulting wear on the 0-ring seals. If a leak should develop, a complete overhaul requiring six months to a year of down time would be necessary.

Because of the intermittent operation of the reactor, it has not been possible to eliminate temperature changes, but efforts have been made to limit the magnitude of fluctuations. The circulating pumps for the reactor cooling water add about $75 \mathrm{~kW}$ to the water and thus reduce the rate at which the water loses temperature.

To stabilize the cooling water temperature, several problenis had to be consideret:

1. If the cooling tower was run while the reactor was off and the reactor cooling water was circulated, the reactor cinoling water would drop below an acceptable temperature.

2. If the cooling tower was shut down when the reactor was down, the intermittent drying would cause the wood in the tower to split and encourage delignification and dry rot.

3. If the cooling tower was operated, but was bypassed by the reactor cooling water, it would be subject to freezing.

II . CRITERIA

The cr:teria developed from these considerations were:

1. The tower must be kept moist to eliminate splitting of the wood and to el iminate conditions favorable to delignification and 
dry rot.

2. The tower must be kepi from freezing.

3 . The rate of temperature loss when the reactor is off must be minimized.

\section{SOLUTIONS}

The first problem to be resolved was that of keeping the wood in the tower from drying out while the tower was shut down. In August, when freezing was not a problem, a pair of lawn sprinklers was installed in the top of the tower (Fig. 2). They per. formed adequately by keeping the wood wet with a minimum of power and water requirements, and allowed time to prepare a solution to the problems for the winter months.

Successful winter operation became possible when a bonnet, similar to a shower cap, was installed to restrict air flow across the fan. Tubular aluminum struts (Fig. 3) were formed into a domeshaped frame resembling a tent frame. Plastic sheet was tied over the frame. The temperature drop in the cooling water during the night was reduced by more than half.

A canvas top was eventually constructed to replace the plastic one (Fig. 4). The canvas was sturdier and easier to manipulate (Fig. 5). No significant difference in operational performance was noticed between the plastic and canvas tops.

Soon after use of the first bonnet, circula. ting water was run through a simple home-type water heater. The cooling water actually increased in temperature during the night, so this auxiliarv hoat source was discarded as unnecessary. Also, plans to heat basin water with a set of plate $z a i ! s$ connected to a boiler were discarded.

The rext installation was a set of plywood shutters over the louvers. The shutters could be opened and closed from the ground by the use of ropes (Fig. 6). Temperature stability of the cooling water was much improved. An added benefit was increased humidity. With the bonnet on and the shutters closed, evaporating water would condense on the wood to keep it wet or moist.

During very cold nights the shutters would freeze while closed. If a heat load was applied the next morning, heat from the inside woul t melt the ice before cooling capacity was reached. The shutters could then be opened sequentially to vary the cooling capacity as needed.

IV. OPERATIONAL DATA

The performance of the modified cooling tower was checked on New Year's Eve. The reactor had been off on December 31, 1974 and the water in the reactor cooling chamber had reached $23 \mathrm{C}$. Lats in the afternoon the reactor was run for about 1 hour while the water was circulated through the cooling tower heat exchanger, heating the basin water. When the water reached $39 \mathrm{C}$ the reactor was shut off but the circulating water continued to ci.culate. In two days the basin water temperature and the circulating water temperature had reached $21.5 \mathrm{C}$. The rate of temperature loss was initially linear but became asymptotic as it dropped below $25 \mathrm{C}$. Nighttime ambient temperatures dropped as low as $-23 \mathrm{C}\left(-10^{\circ} \mathrm{F}\right)$ during the holidays.

More recent experience has shown that much higher temperatures can be maintained by throttling the circulating water. On weekdays, when outside temperatures may fall as $10 \mathrm{w}$ as $-18 \mathrm{C}\left(0^{\circ} \mathrm{F}\right)$, the overnight temperature in the cooling water seldom drops below $35 \mathrm{C}$. Ev $=n$ on weekends, cooling water temperatures seldom drop below $32 \mathrm{C}$.

\section{SUMMARY}

There are occasions when intermittent operation of a cooling tower is desirable. Modifications have been developed to allow a cooling tower to be operated intermittently summer or winter, without drying out or freezing. In addition, with a little experimenting, water temperature can be maintained at a reasonably constant level, if desired. The use of a bonnet to restrict air flow across the fan and of shutters to restrict air flow across the louvers will reduce evaporation and provide a moist environment for the wood. 


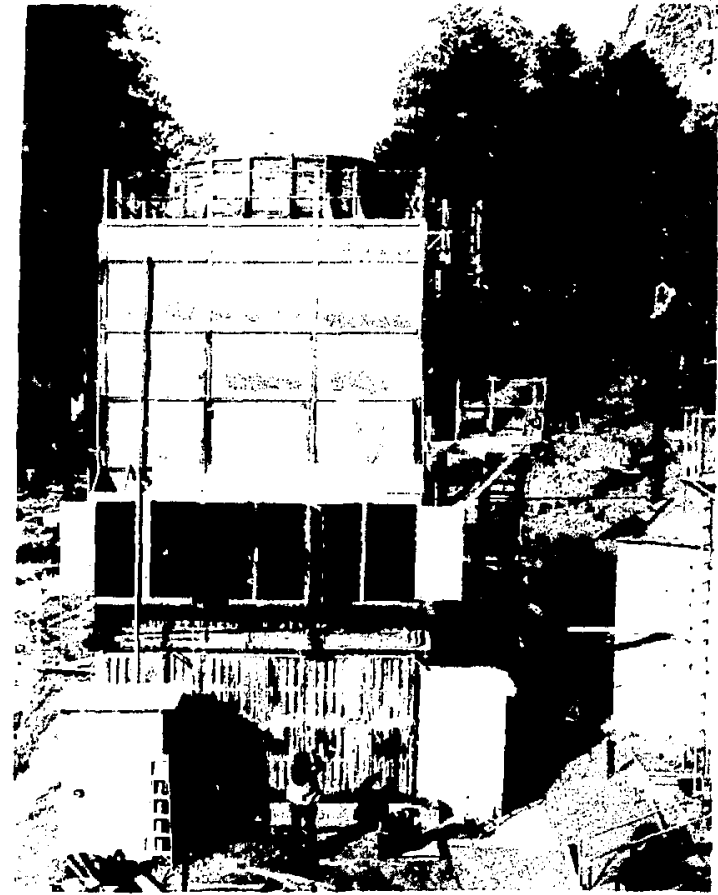

Fig. 1. Cooling tower for nuclear reactor at Omega site, LASL. This cooling tower was manufactured in 1957 by Fluor Products Company (Model IFPAZ 1123-1824 CCLP). It has a $26-\mathrm{ft}$ by $20-\mathrm{ft}$ basin and is rated at 2265 $\mathrm{gpm}$. The shutters are being opened from the ground with ropes.

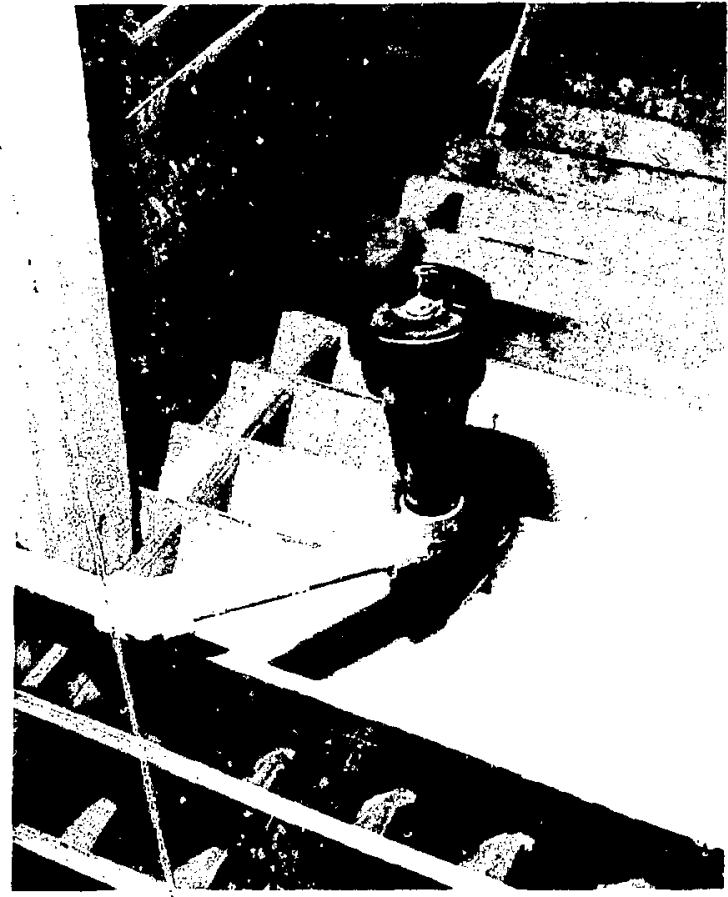

Fig. 2. Ork of the sprinklers is shown above the fill. Sprinklers were used in summer to kee $\rho$ the wood moist.

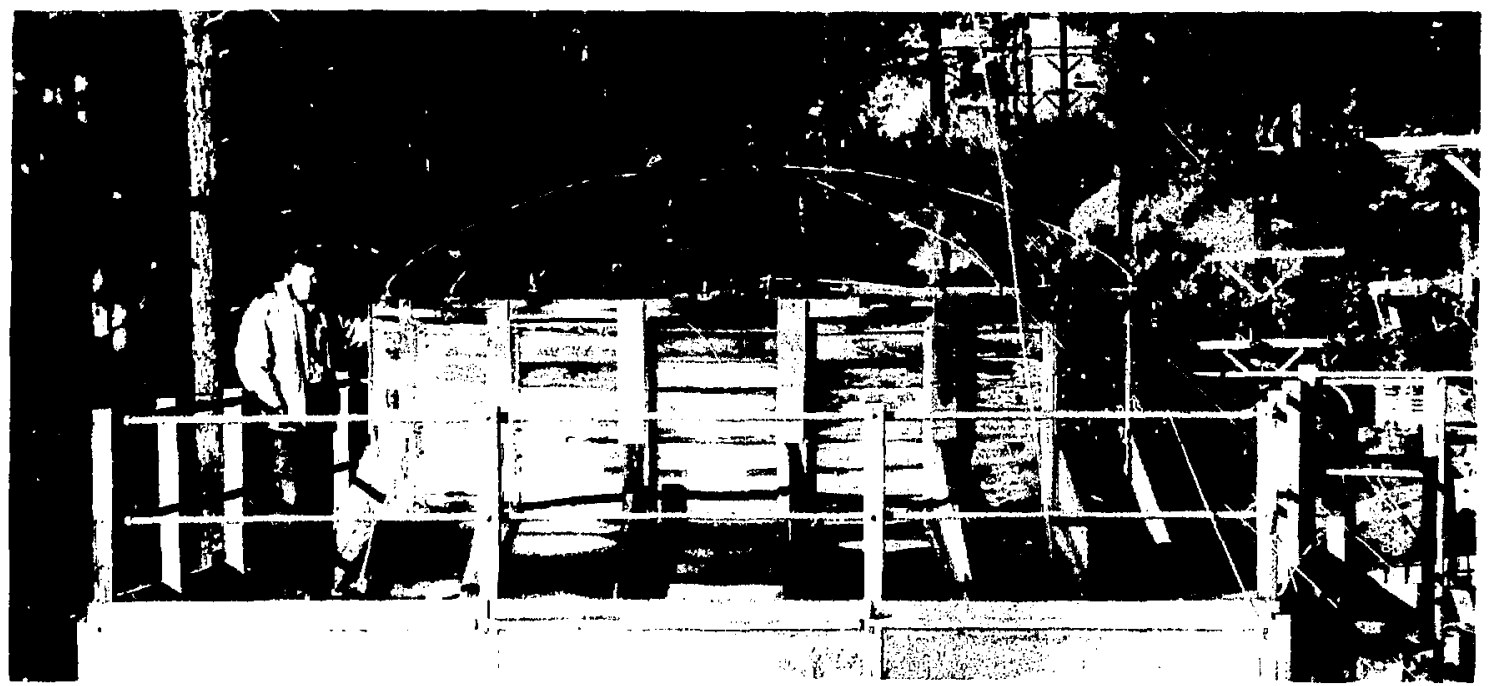

Fig. 3. T.J. Brunton, who butit the modifications for the cooling tower, is shown with the tubular aluminum frame which provides support for a canvas bonnet over the fan. 


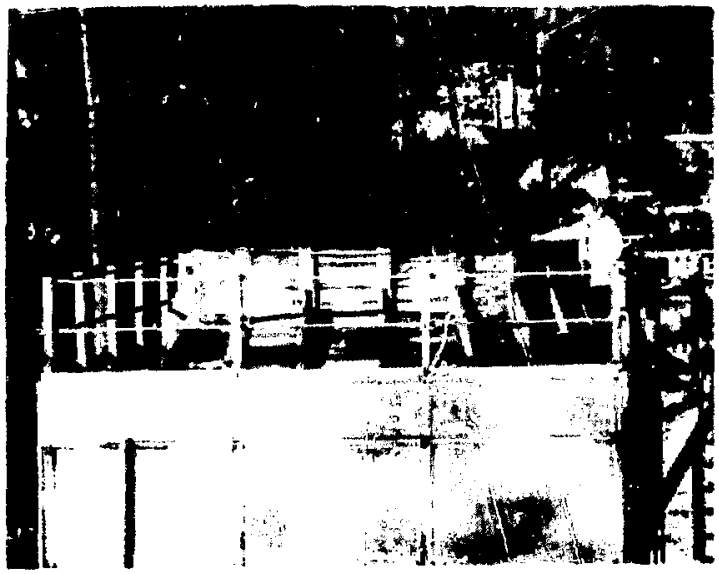

Fig. 4. With the canvas bonnet in place, afr flow across the fan is effectively reduced. An earlier bonnet had boen constructed from plastic. No significant difference in performance between tops was noticed.

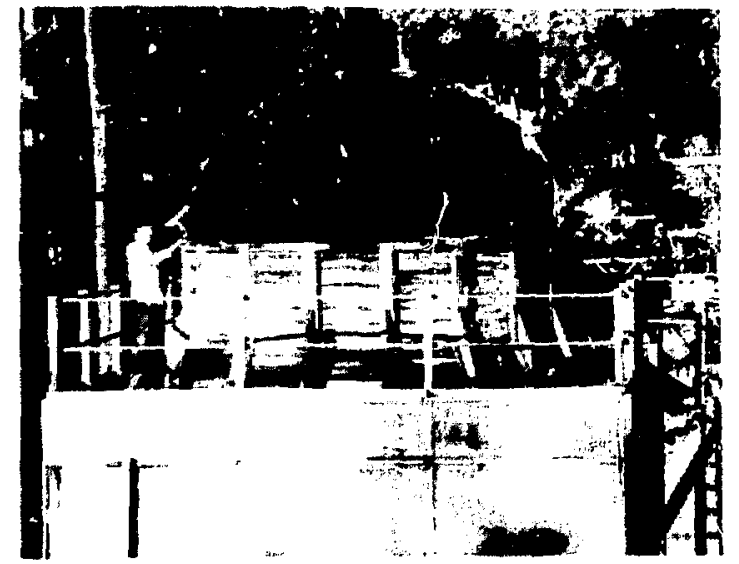

Fig. 5. With a swing of the arm, the canvas bonnet can be draped over the aluminum frame.

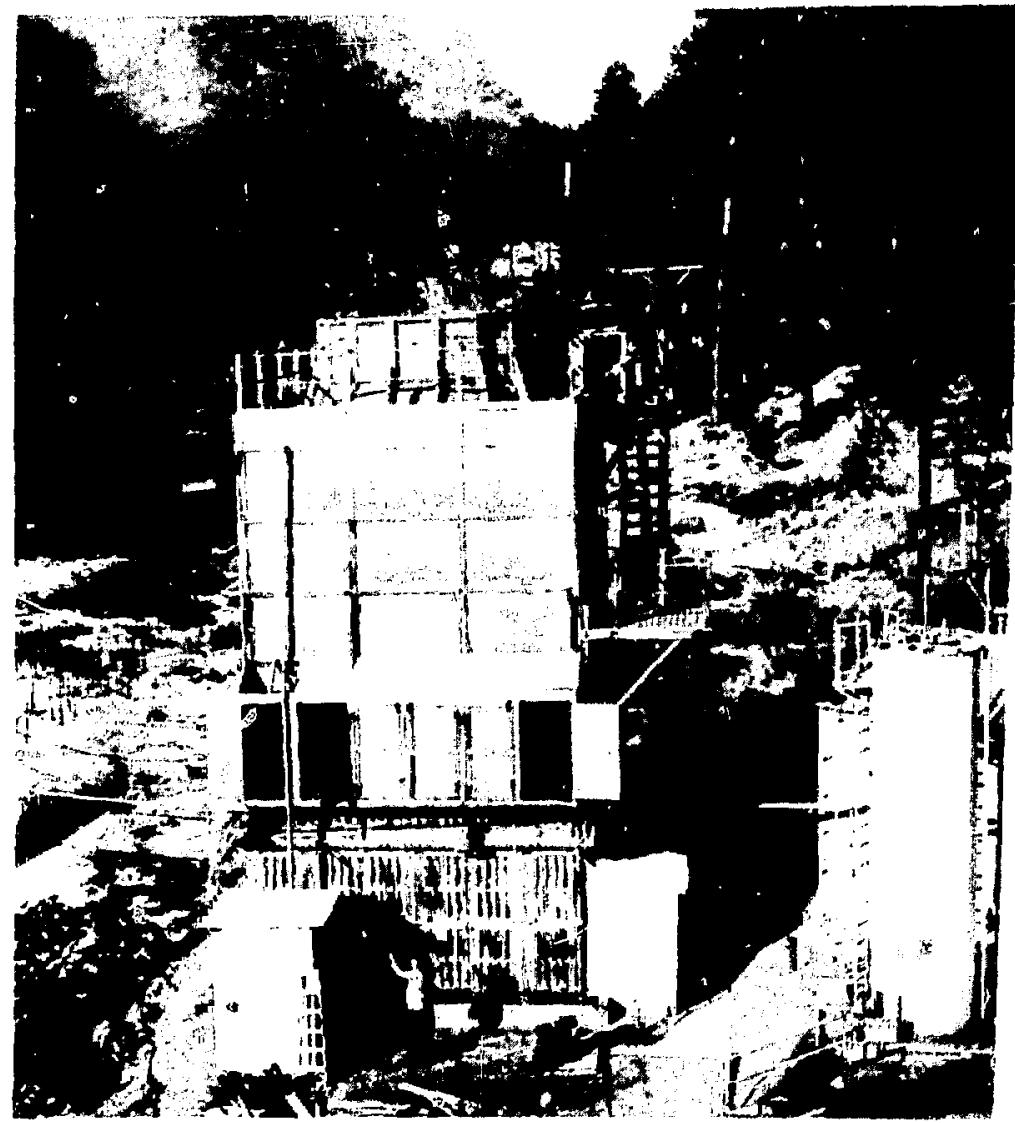

Fig. 6. The shutters may be opened sequentially to increase cooling capability during cold weather as needed. When the cooling tower is not being operated, the shutters are closed to block air flow which would produce freezing temperatures. 